\title{
GIFs as floating signifiers
}

\author{
Camelia Gradinaru \\ Department of Interdisciplinary Research in Social Sciences and Humanities \\ Alexandru Ioan Cuza University of lași \\ Lascăr Catargi no. 54, 700107, laşi, Romania \\ e-mail: camelia.gradinaru@uaic.ro
}

\begin{abstract}
This paper investigates GIFs that use famous paintings and art collages in order to discern if their possible interpretations justify the label of 'floating signifiers'. For this purpose, I explain what 'floating signifier' means and describe what happened with the term when it was correlated with the issues of information and digital materiality. Thus, in new media, the parallel term for 'floating signifier' is Hayles's 'flickering signifier'. In a subtle manner, GIFs represents perfect instantiation of both concepts. The paper also addresses the main "portrait" of GIFs, examining them in both online (Tumblr, Instagram, Facebook) and offline discursive contexts. The signifieds attributed to particular examples of GIFs, and to GIFs in general, delineate their profile in terms of floating signifiers.
\end{abstract}

Keywords: GIF; floating signifier; flickering signifier; floating chain of signifieds; intertextuality; parody; art collage

\section{Introduction}

Visual content represents a serious challenge for audiences and for academics. In a supersaturated world of signs, cyberspace has multiplied the possibilities of creation, dissemination, and sharing, and has become a vast reservoir of various types of signs. The visual is a growing trend on social media and it feels obvious today that "the contemporary visual social media landscape replete with GIFs, selfies, emoji, and more is the latest iteration of networked communication with a long-running theme: we have always found ways to be visual online" (Highfield, Leaver 2016: 48). The prominence of images raises questions about the relevance of perspectives and methods through which we can accurately interpret them. Online images may be analysed in the frames offered by semiotics, discursiveness or visual rhetoric, and quite frequently we use combined tools that emanate 
from these fields. Many other disciplines, such as psychology or marketing, have provided valuable insights in this quest, pointing out the need for interdisciplinary approaches.

Semiotics is one of the main disciplines considered well equipped for such an investigation. This paper analyses GIFs that use famous paintings and art collages from a semiotic perspective in order to discern if their possible interpretations justify the label of 'floating signifiers'. For this purpose, I will explain what 'floating signifier' means and depict what happened with this term when it was correlated with the issues of information and digital materiality. The interpretation of GIFs in online (Tumblr, Instagram, Facebook) as well as offline discursive contexts, in a complex and multi-layered analysis, will be detailed in the second part of this paper. The signifieds attributed to particular examples of GIFs and to GIFs in general delineate their profile in terms of floating signifiers.

\section{What is a floating signifier?}

The relationships between the signifier and the signified represent a crucial axis of debate in semiotics. The semioticians who adhered to Saussure's theories have asserted the arbitrary relationship between the signifier and the signified. This perspective has flourished in postmodern theories, where the signifier and the signified are detached or disconnected from each other. Lacan, Barthes and Derrida are often mentioned for their interpretations in which signs do not need to be fixed in any particular signified, the "free play" of signifiers being the only authentic semiotic movement. Moreover, postmodernism is conceived of as having a basis in the semiotic of the empty and floating signifier which appears disjointed from the signified; this split represents the origin of the "fluidity" as "principle" of the postmodern current (Nusselder 2009: 61).

Lévi-Strauss originated the term 'floating signifier' when he discussed symbolic thought in Introduction to the Work of Marcel Mauss - the concepts such as 'mana', 'wakan', 'orenda' are challenging our rationality, being caught between "the disability of all finite thought" and "the surety of all art, all poetry, every mythic and aesthetic invention" (Lévi-Strauss 1987: 63). At first inspection, this seems to indicate a kind of unaccountable incoherence in native thought, a limit or an aporia. In fact, these notions have the power of working with contradictions, engaging a "semantic function". Lévi-Strauss got the inspiration from Mauss himself, for whom all social situations have to be comprehended and integrated into language. Furthermore, Mauss emphasized that the relationship between the signifier and the signified may be evasive, transient or evanescent. For Lévi- 
Strauss, the floating signifier is a "symbol in its pure state" (Lévi-Strauss 1987: 63 ), and all the concepts that function as floating signifiers are akin to algebraic symbols, because they

\begin{abstract}
[...] occur to represent an indeterminate value of signification, in itself devoid of meaning and thus susceptible of receiving any meaning at all; their sole function is to fill the gap between the signifier and the signified, or, more exactly, to signal the fact that in such a circumstance, on such an occasion, or in such a one of their manifestation, a relationship of non-equivalence becomes established between signifier and signified, to the detriment of the prior complementary relationship. (Lévi-Strauss 1987: 55-56)
\end{abstract}

Mehlman (1972: 24) thought that the concept of the floating signifier implied a relevant turn to the Saussurean usage of 'significant', representing the arbitrary background of language that comes to the fore in speech. For Mehlman (1972: 37), Lacan's use of the concept supposes a kind of complexity that integrates the uses of Saussure and Lévi-Strauss. Barthes brings the discussion into a field propitious for our investigation - the image. As a representation or a copy, the image embedded a problematic link with meaning: on the one hand, the image is perceived as an artless system in comparison with language; on the other hand, the image is conceived of as an inexhaustible system of significations, resistant to a final decoding. Starting from here, Barthes (1977a: 32) affirms that "the image is in a certain manner the limit of meaning, it permits the consideration of a veritable ontology of the process of signification". What is relevant for all images is their inner polysemy, their abundance of interpretations and ideas. In this respect, they are always carrying a level of uncertainty concerning their meaning and they require many strategies of fixing to anchor some of these meanings. Thus, the images imply "underlying their signifiers, a 'floating chain' of signifieds, the reader able to choose some and ignore others" (Barthes 1977a: 39). The floating chain of signifieds is the immediate consequence of the endless interpretation of merely non-linguistic signs, because the "anchorage" is easier for the linguistic messages (and even for advertisements or press photographs). Language has the power to elucidate the senses, even if it is selective and sometimes the anchorage is profoundly ideologically biased.

The concept of anchorage seems to be in a close relationship with the term 'nodal points' (Laclau, Mouffe 1985), a concept inspired by Lacan's (1955) expression 'points de capiton'. The nodal points ensure the possibility of meaning, being "privileged signifiers that fix the meaning of a signifying chain" (Laclau, Mouffe 1985: 112). For Laclau and Mouffe, any kind of discourse tries to become a centre, a dominant frame, to set up partially the path of understanding. At the 
same time, there is an overflow of meaning that makes reaching the saturation point improbable. Such ambiguous signifiers are the floating signifiers, for which "either an overdetermination or an underdetermination of signifieds prevents them from being fully fixed" (Laclau 1996: 36). The floating signifiers result from "the unfixity introduced by a plurality of discourses" (Laclau 2000: 305), moving and challenging the frontiers of discursiveness. Even if the concepts of floating signifier and empty signifier can overlap, the former is never empty (Laclau 1996: 36), but only equivocal or ambiguous. An empty signifier is one that tends to represent a heterogeneous area, being universal and losing any possibility of referring to a particular meaning. On the contrary, the floating signifier shows a large extent of linkage to many different projects, being full of diverse possibilities.

\section{Signifiers and signifieds in cyberspace: Floating or flickering?}

Whether various users can share meaning online represents a central interrogation nowadays. In terms of the social semantics of the web, this question becomes: "[...] can we define a theory of senses for the Web on the basis of use?" (Halpin, Thompson 2009: 28). The growing of online content, its astonishing diversity, and the heterogeneity of the public make it difficult to imagine the entire map of all the meanings that arise. Thus, users have to discern among a plethora of language games and their subsequent online social practices.

The move to the screen as the dominant mode of communication gave an important role to images in general. Of course, as Kress argued, images have always been present in our culture as elements filled with meaning. The difference is that "at the moment image is coming ever more insistently into the domain of everyday communication, as a full means of representing ideas, information and knowledge" (Kress 2003: 20). Thus, we can talk about multiple modes of communication, language not being the main mode anymore because it cannot decode the entire meaning of a multimodal message. In the new media age, the theoretical modification is "from linguistics to semiotics - from a theory that accounted for language alone to a theory that can account equally well for gesture, speech, image, writing, 3D objects, colour, music and no doubt others" (Kress 2003: 35-36). Language becomes just a mode of representation among many other possibilities; meanwhile, semiotics is better able to conceive not only forms, but forms-and-meaning. The convergence of media (Jenkins 2006) proves to be a key factor that makes the "conversation" of old and new forms of media, types of materiality and tools possible. At the same time, the very concept of creativity constitutes a consequence of these actions, and it represents an element found in 
the combination of resources, but also in the design and production of messages. In other words,

creativity becomes normal and unremarkable in the very instance of sign-making. Innovativeness, in the sense of producing 'the new', is, equally, an automatic consequence of sign-making: all signs are new, all combinations of resources in the making of a specific message are likely to be new. (Kress 2003: 169-170)

These traits are totally visible in the case of GIFs and art collages, where the fusion of styles, different fragments, and regimes of meanings creates new semiosis. The modes of representation and communication mixed in these two forms can be very dissimilar and the simple act of reception required, in fact, a complex hermeneutic path.

Digital media have hybrid characteristics emanating from visual, textual or figural multimodal possible displays; they are "pure simulation" or "new hieroglyphic mixtures" (Rodowick 2001: 37). The digitally semiotic environment became a distinctive domain that has to be understood and mastered, even if we do not possess all the necessary tools in order to undertake this task. As Rodowick (2001: $\mathrm{x})$ noticed,

[...] contemporary electronic media were giving rise to hybrid and mutant forms that semiology was ill equipped to understand. Moreover, the creation of a social theory and mode of philosophical analysis adequate for understanding the new images also seemed to require a deconstruction of the aesthetic philosophy.

GIFs, for instance, have an interdisciplinary content and we can understand them with the help of various filters of interpretation (cinema, aesthetics, communication, semiotics, linguistics, philosophy and so on). These disciplinary fields prove insufficient for the formulation of a comprehensive account of the digital signs. Moreover, the emergent mass culture has its own trends and specific forms of knowledge that are exchanged and communicated. All of these factors design a kind of map where semiotics has a dominant role, because

[s]emiotics is 'the mathematics of the humanities' in the sense that it provides an abstract language covering a diversity of special sign-usage (language, pictures, movies, theatre, etc.). In this capacity, Semiotics is helpful for bringing insights from older media to the task of interface design, and for defining the special characteristics of the computer medium. (Andersen 2001: 419)

New media challenged in a fresh way the breakdown of traditional distinctions, such as the difference between linguistic and plastic representations. Also, they 
challenge radically the relations of signifier to signifieds and their conventional combinations (Nusselder 2009: 61).

In the context of substituting the "absence - presence" model of Western thinking with the "pattern - randomness" model of information technologies, Hayles (1993) made some observations that are very fruitful for our inquiry. Based on the specificities of the digital (im)materiality, the general model of signification in the electronic environment does not fit anymore with the one-to-one correspondence between the signifier and the signified. The new media radically re-discussed the signifier - signified dynamic. Going further than the floating signifier seen in Lacanian terms, Hayles (1993: 76) states: "information technologies create what I will call flickering signifiers, characterized by their tendency toward unexpected metamorphoses, attenuations, and dispersions. Flickering signifiers signal an important shift in the plate tectonics of language". The digital "fluidity" causes the signifier to flicker rather than float and to have an inner play of difference. If Barthes talked about the floating chain of signifieds, informatics works with a "flexible chain of markers bound together by the arbitrary relations specified by the relevant codes" (Hayles 1993: 77). Thus, the signifier is open to differences, to a "flickering signification" too, one that represents "the progeny of the fascinating and troubling coupling of language and machine" (Hayles 1993: 80). In poststructuralist fashion, Hayles considers that there is no original text in cyberspace, but only flickering signifiers, "whose transient patterns evoke and embody what Trow has called the context of no context, the suspicion that all contexts, like all texts, are electronically mediated" (Hayles 1993: 89-90). This flare of signifiers is derived from the specificities of information and from the principles of new media (Manovich 2001).

Hayles discussed flickering signifiers in relation to a large context of embodiment and materiality, in her quest of restoring their importance. Hayles (1999: 2) asserted that "information lost its body", and the eradication of embodiment from the early writings in new media studies represents an "accident of evolution we are now in a position to correct" (Hayles 1999: 12). In this large framework of her analysis, digital signifiers flicker at many levels, not only at the semiotic level, but also through the material basis of their appearance on a screen. Also, this peculiarity of the digital signifiers is used in order to emphasize their malleability and versatility, very noticeable in the case of hyperlinks. Tree-like or network structures expose easily the idea of flickering signifiers for users; in the same time, if we add the covert semiotics of information technologies - the algorithms as interpretation process of encoded information into computable signifieds - we can notice that semiotic processes take place at many levels simultaneously. 


\section{The land of GIFs}

GIF - Graphics Interchange Format - was created initially for the simple purpose of integrating images into web pages. Today, they have become a really important part of Internet culture, with a wide range of meanings: communicational, aesthetic, cinematic. GIF is, in fact, the true expression of a paradox: it is a poor format, with no remarkable options, but still enjoys huge proliferation and valorization. GIFs are short, repeat the same gesture ad infinitum, have only 256 colours and are small in size. Neither do they have any audio features, being a mute form of interaction. GIFs are very popular not only on Tumblr or blogs, but also on social networking sites, being widely used as short succinct communicative tools, mainly in the area of gestures or emotions, as a convenient set of interpersonal exchanging of codes. GIFs can be static, but also animated, the last type having a wide popularity, giving the impression of a continuous movement, a cinematic loop. They are more engaging than other types of media (Bakhshi et al.2016). GIFs are somewhere between still and moving images, being a "kind of phenomenological hybrid of photography and film" (Huber 2015) ${ }^{1}$.

The majority of definitions that have been given to GIF are technical, describing the characteristics of this image format (Furht 2008: 326), such as the number of colours, the mode of compression, additional features (animation, interlacing) or disadvantages (limited range of colour that a single image can represent). The definitions that should encompass the entire range of roles, activities, and meanings are very scarce. Also, they are significantly different, emphasizing various utilities. From my standpoint, Eppink's approach remains comprehensive enough:

The GIF began as a data format, certainly: the Graphics Interchange Format is a standard for encoding and decoding a string of $1 \mathrm{~s}$ and 0 s. But today the GIF casts a much longer shadow. It has an ethos, a utility, an evolving context, a set of aesthetics. GIFs are encountered not in theaters or in living rooms, but on networked screens that are physically private but socially public. They are not simply viewed; they are created, used, posted, collected, copied, modified, performed. Today 'GIF' is typically used to mean an animated GIF file or an otherwise short, silent, looping, untitled moving image. It has a creator who is unknown or deemphasized; it is encountered by an individual viewer on a personal screen where it is surrounded by text and other media; and it is shared casually as a form of identity-making, a cinema of affiliation. (Eppink 2014: 298)

1 Huber, Linda 2015. Remix culture \& the reaction GIF. Gnovis. Journal of Communicaton, Culture, and Technology. Available at http: //www.gnovisjournal.org/2015/02/25/remixculturethe-reaction-gif/. 
At a glimpse, GIFs represent the perfect instantiation of the spirit of our times that can be depicted by shortness, speed, abbreviation, distraction. As Baudrillard (1994: 80) pointed out, "information devours its own content. It devours communication and the social [...]. Rather than creating communication, it exhausts itself in the act of staging communication. Rather than producing meaning, it exhausts itself in the act of staging meaning". Thus, GIF would be a good example that contributes to the "ecstasy of communication", a kind of simulacrum that "devours" the original and transforms everything into pallid copies, stilling the authenticity of all communicative and semiotic exchanges. Copy and paste practices have already transformed new media into an arena of remix culture. The Internet would be the final instantiation of the hyperreality, where signs refer to one another in a circular process. Nevertheless, people tend to prefer the virtual presence to the detriment of the natural presence, because media and communication technologies offer more involving experiences than everyday life.

Yet when we label GIFs only as an epitome of our frenzied epoch, we also miss the plethora of meanings hidden by their usage. For Hagman² (2012), GIF illustrates how the medium (the technology) intervenes in the content of the original, with spectacular new outputs. In this respect, GIF is about creation, differentiation, and metamorphosis and not about recycling. It is a digital gesture that acknowledges the fascination of cinematic movement, being "the manifestation of pure mediality" (Hagman 2012) and communicability. Animated GIFs constitute a looped repetition that holds on to the moment that is repeated; in this sense, the storytelling is somehow ejected from the scene. The animated GIFs have as a mainstream basis scenes from films, award shows, cartoons, art, different types of speech, and communicate simple emotions in a certain quest of filling the gap caused by the absence of nonverbal cues in computer-mediated communication. GIFs produce decontextualization, extracting just one movement or expression in order to highlight it. GIF creation can be considered a "form of textural poaching, a new reception practice involving skimming off and repurposing top-of-the-mind content" (Gillan 2016: 9). The power of movement creates a matrix of meanings and for that reason GIF is a medium of support, circulation, and sharing. The relationships between GIF and the early cinema reveal the actuality of remediation (Bolter, Grusin 1999) and the inner "conversation" between old and new media. Also, GIF can be interpreted as a form of nostalgia for previous media, producing a kind of "vinyl chic" seduction for Internet users.

2 Hagman, Hampus 2012. The digital gesture: Rediscovering cinematic movement through GIFs. Refractory. Journal of Entertainment Media. Available at http: //refractory.unimelb. edu. au/ 2012/12/29/hagman/. 
Rourke (2012) has analysed five types of GIFs: type I: "classic" (small in size, with few frames); type II: "frame capture" (using scenes from pop culture, mainly); type III: "Art GIF" (larger in resolution and connected to cinema heritage); type IV: "glitch" (badly encoded GIFs producing strange aesthetic phenomena); type V: "mash-up" (a combination of all the previous types). Eppink (2014) has depicted a short history of GIFs including as landmarks the following forms: "glitter GIFs" (digital stickers imitating sparkling glitter), "wobble GIFs" (producing a stereoscopic effect by alternating images), "cinemagraphs" (one element of the image is in motion while the rest remains still), "listicles" (GIFs organized on a particular thematic structure and chiefly popularized by Buzzfeed), "reaction GIFs" (loops of body in motion excerpted from films, TV or shows, expressing emotions), "Art GIF" (a form of Internet Art, with particular aesthetic messages). The lists with types of GIFs are not typologies stricto sensu. Rather, they are inventory practices or forms of GIFs without necessarily organizing them in logical classifications, with a unique criterion for each level of classification. As we can easily notice from the above cases, this (minimal) intention to systematize them is either operational (authors indicate how one can create a specific type of GIF) or historical (a mere diachronic presentation). When we examine the categories obtained, we can see that they overlap (for instance, a reaction GIF could be also an art GIF).

GIFs are used in computer-mediated communication and mobile communication, with similar functions as emoticons. Around 2011 GIFs were posted as responses to messages or even as a substitute for text, expressing simple ideas or emotions. In a fruitful poststructuralist way combined with the theory of shared gift economy of the web (Uhlin 2014), "a successful GIF is one that is shared, eclipsing its creator to become an essential part of a cultural conversation. The result is a digital slang, a visual vocabulary unencumbered by authorship, where countless media artifacts are viewed, deployed, and elaborated upon as language more than as art product. Even though individuals process the pixels, communities make the GIFs" (Eppink 2014: 301). Reaction GIFs represent forms of personal expression, a tool for interpersonal communication that captures bodily and emotional replies and also underlines humour. These GIFs are meant to be taken as the user's own actions and affects, which in face-to-face conversations occur naturally and do not need demonstration. Thus, in this very point, GIFs distinguish themselves from emoticons, because they are "embodied enactments in text-mediated communication" (Tolins, Samermit 2016: 75), while the later are "symbolic and abstract in nature rather than quotative" (Tolins, Samermit 2016: 77). GIFs are acting as "visual demonstrations", as visual depiction of emotions and actions, being inserted successfully in mediated communication. What is surprising is the way in which users decide to insert embodied behaviours, affects, 
and actions of others; that is to say, people use the bodies of others to make their personal discussions meaningful. Unexpectedly, body and materiality appear in the practical use, but in a quoted form. This very particularity - the citationality indicates the pragmatic use of GIFs and their reliability. Users are sure that their communicative intentions will be correctly interpreted and that the recipient will assert in a univocal way one signifier to each signified. What is worth emphasizing is that "these intertexts do not necessarily need the observer to be familiar with the source to understand the new constructions" (Highfield, Leaver 2016: 53). People who recognize the source of GIFs are opened to additional levels of significance and may construct a network of intertextual meanings. Thus GIFs have the role of "visual enthymemes" (Blair 2004: 59), an abbreviated syllogism that easily conducts the public toward the conclusion. Also, GIFs created a particular transmedia literacy practice (Gürsimsek 2016) that illustrates perfectly the "vernacular creativity" (Burgess 2006) that can be deciphered by the instrumentality of "social semiotics" (Halliday 1978).

In general, Internet memes are considered as a form of subversive communication in an extended participatory culture (Huntington 2013) ${ }^{3}$, that use intertextuality, parody and pastiche in order to react to dominant structures and canons in uncommon ways. GIFs are a part of the online gift economy and also open "an inquiry about the divide between art and commerce, as well as between play and work" (Uhlin 2014: 517). Thus, GIFs recall the animistic qualities of early cinema (Uhlin 2014: 518), and illustrate Benjamin's "room-for-play", whose axis is the repetition itself. This "joy" of playing with images, their sharing without the claim of ownership, the creation of meaning in the network of different usages represent some characteristics that transform the users into "dispossessive spectators" (Uhlin 2014). Part of a large playground, the creators and the spectators of GIFs distribute them in a parallel way to the official media or mainstream channels.

In the case of GIFs that reinterpret works of art, "hyperaesthetics" may account for the complexities of the conjunctures between art and new media. Thus, two aspects are highlighted: the relevance of the medium and the Möbius-like existence of digital unfinished paths. Reusing Barthes's ideas, Lunenfeld emphasizes the process rather than scope, "the state of suspension" rather than resolution (Lunenfeld 2000: 8). In this "era of digital ubiquity", hyperaesthetics cannot be applied to stable forms, but, on the contrary, to fluid and movable forms, such as GIFs. The blurring of traditional categories and boundaries is visible in art

3 Huntington, Heidi E. 2013. Subversive memes: internet memes as a form of visual Rhetoric. Selected Papers of Internet Research 14. Available at https://spir.aoir.org/index.php/spir/article/ view/785/pdf. 
GIFs and this is the reason why a classical aesthetics would fail to interpret them accurately. As an alternative, hyperasthetics encourages a "hybrid temporality, a real-time approach that cycles through the past, present, and future to think with and through the techno-cultures" (Lunenfeld 2001: 29) and also a form of "theoretization in real-time" (Lunenfeld 2001: 37). Pamela G. Taylor (2004: 339) has compiled an interesting list of concepts associated with hyperaesthetics and technomediation, which includes such terms as: hypermediacy, erasure, transparency, movement through the space, repurposing and rearranging, multi-perspectives, repetitive viewing, cycling and so on. Unsurprisingly, many of them succeed in describing GIFs; for instance, if "repurposing and rearranging describe the process of altering meanings associated with images and objects through and with technological media" (Taylor 2004: 339), GIFs are the best instantiation of these traits, because they reuse fragments in order to change the interpretation, to modify the signification and, ultimately, to transform the originals into floating signifiers.

\section{GIFs: The unbearable lightness of meanings}

From the semiotic point of view, there are important differences between the categories of GIFs. Thus, the reaction GIFs tend to preserve one dominant meaning and to transmit this meaning in conversations, being a sort of collection of primary emotions and bodily gestures. Moreover, the frames used represent a kind of universal language of affects, easy to decipher by almost any participant in conversation. In this case, the reaction GIFs suppose a relation of correspondence between the signifier and the signified; in other words, their meaning is quite stable. The reaction GIFs act as "particular kind of semantic unit ready to be inserted into the flow of any conversation, like a kind of uber-emoji. It is not just a form of entertainment - it is a tool which allows us to enhance and augment our primarily text-based online communications" (Huber 2015). Being a semantic unit, reaction GIFs are practically means of communication and not a work of art. They intervene in an almost natural way in digital communication, referring to an easy decrypted signification. In Roland Barthes' (1977b) terms, we can affirm that reaction GIFs have "obvious meaning".

Unlike reaction GIFs, art GIFs exploit more the strategies of intertextuality, irony, pastiche and collage, and thus the meanings are not fixed. Hagman (2012) observed that GIFs may be characterized by the Barthesian concept of "third meaning" that can be achieved through the film still, the fragment. The third meaning is an obtuse one, a "supplement that my intellection cannot succeed in absorbing, at once persistent and fleeting, smooth and elusive" (Barthes 1977b: 
54), "a signifier without a signified" (Barthes 1977b: 61). Hence the difficulty of interpretation, that is suspended between the description and approximation; Barthes terms this "a state of perpetual erethism" (Barthes 1977b: 62) that posits a fluctuation in considering the signifier either empty or floating. Also, the obtuse meaning represents "the epitome of a counternarrative" (1977b: 63); as we have seen earlier (Hagman 2012), GIFs are short of any narrative telos. The third meaning has traits that mirror the characteristics of the GIF: "[...] disseminated, reversible, set to its own temporality, it inevitably determines (if one follows it) a quite different analytical segmentation to that in shots, sequences and syntagms (technical or narrative) - an extraordinary segmentation: counter-logic and yet 'true"' (Barthes 1997b: 63).

The absence of a fixed signification, the gap that remains to be filled represents actually a form of power and not a frailty of GIFs. The people who produce them put to work, among other things, the process described by Lévi-Strauss: the emptying, the cleaning of the meanings of a given image. For GIFs emanating from famous paintings, the erasure of the initial context and the suspension of the dichotomies between high and low art constitute important strategies that set the images free from the canon. In this vein, GIFs are totally relocated to interpretations, because the standard or classic hermeneutics of their components does not hold anymore. Thus, they have a "zero symbolic value", becoming signs that need a "supplementary symbolic content" (Lévi-Strauss 1987: 63). The destabilization of the original category of the images used (famous paintings that belong to the universal patrimony) induces a highly instability of the referent. In this sense, they become floating signifiers - we can notice a relevant inadequacy between the signifier and the signified, also the audience can propose different meanings for the same image.

\section{A micro-analysis of GIFs in different contexts}

Many terms have been labelled as floating signifiers: 'race' (Hall 1997) 'citizenship' (Moraes 2014), 'people' (Laclau 2005), 'participation' (Carpentier, De Cleen 2007), 'religion' (Topolski 2014), 'human security' (Makarychev 2012), 'state' (Mohr 2006), 'ideology' (Žižek 1989), etc. The purpose of the article - to analyse GIFs and other digital art collages as floating signifiers - is based on the inner traits of these digital visual means. In this respect, we do not want to universalize the use of floating signifier or to transform it into an empty signifier, although

4 Hall, Stuart 1997. Race: The floating signifier. Media Education Foundation. Available at www.mediaed.org/assets/products/407/transcript_407.pdf. 
a meta-analysis of the 'floating signifier' in itself should give some interesting insights of the dialectics of 'empty' - 'floating' and its mechanisms of functioning in various contexts. What I want to emphasize is that the term 'floating signifier' cannot be used indiscriminately, as an umbrella term, good for all kinds of general concepts. This label may be applied only after considerable research of the sign, of its occurrences and interpretations in everyday types of semiosis. For these reasons, I have decided to investigate the status of GIFs and digital art collages through an applicative analysis, in which different users, in various life situations of their natural and virtual presence, interact with these signs and express their understanding. Thus, I tried to observe art GIFs in several contexts in order to grasp the signifieds which people tend to associate them with.

\section{Content analysis of comments: Tumblr, Instagram, Facebook}

The first step was to collect comments on GIFs in several corpuses, based on their "location": Tumblr, Instagram, and Facebook. Even if Tumblr is recognized as the favourite site for GIFs, I expanded my investigation to other sites in order to analyse a wider public. On these sites I analysed Shusaku Takaoka's image that reinterprets Mona Lisa and Van Gogh by "relocating" them into a contemporary space and time.

(a) On Tumblr, the collage Van Gogh and Mona Lisa ${ }^{5}$ was posted by several users, with a many likes and reblogs. There were just a few comments, generally expressing a positive attitude towards it.

(b) On Instagram, the Van Gogh and Mona Lisa image has 7,850 likes and 134 comments.

The comments are very short, and in general do not express many thoughts about the content. What is interesting is that people responded using emoticons, a situation that describes a compatibility and a "conversation" between two consecrated ways to communicate visually online. 23 comments are formed exclusively by emoticons, and all of these are appreciative and positive: applauses, smiles, and hearts. 24 comments are composed of text and emoticons, while 60 comments redirect and share the image with other users or raise questions for the artist. In terms of the evaluation of the text, all the comments are eulogistic, the reaction being: "love" (9 occurrences), "cool" (5 occurrences), "funny" (4 occurrences), "awesome" (3 occurrences), "amazing" ( 3 occurrences), "genial" ( 2 occurrences), "fantastic" ( 2 occurrences), "brilliant" ( 2 occurrences), "nice" ( 2 occurrences), and

5 The titles of the images are given by me for the purpose of this article. 
also "sweet", "wonderful”, "superb", "great", "super”, "good”, "beautiful”, "magic”, each of them occurring one time. We can observe a progressive positive line of reception, from "nice" to "good" and even further to other superlatives enumerated. These attributes refer to the collage as a performance in itself, being directed to the artist, but they are also addressing the content and its message. All the same, comments that mention the content are just a few; one user said "He is sad", talking about Van Gogh, another stated: "Why not?" as a sign of remix acceptance, while another person observed "the different atmosphere" of the image in comparison with the paintings. The word that occurred most often as a keyword regarding the content presented was 'couple'. Some users moved this collage even more deeply into contemporaneity by renaming the two characters using pop celebrities. This is actually an example of the ways in which the mash-up culture revealed its practical and viral side.

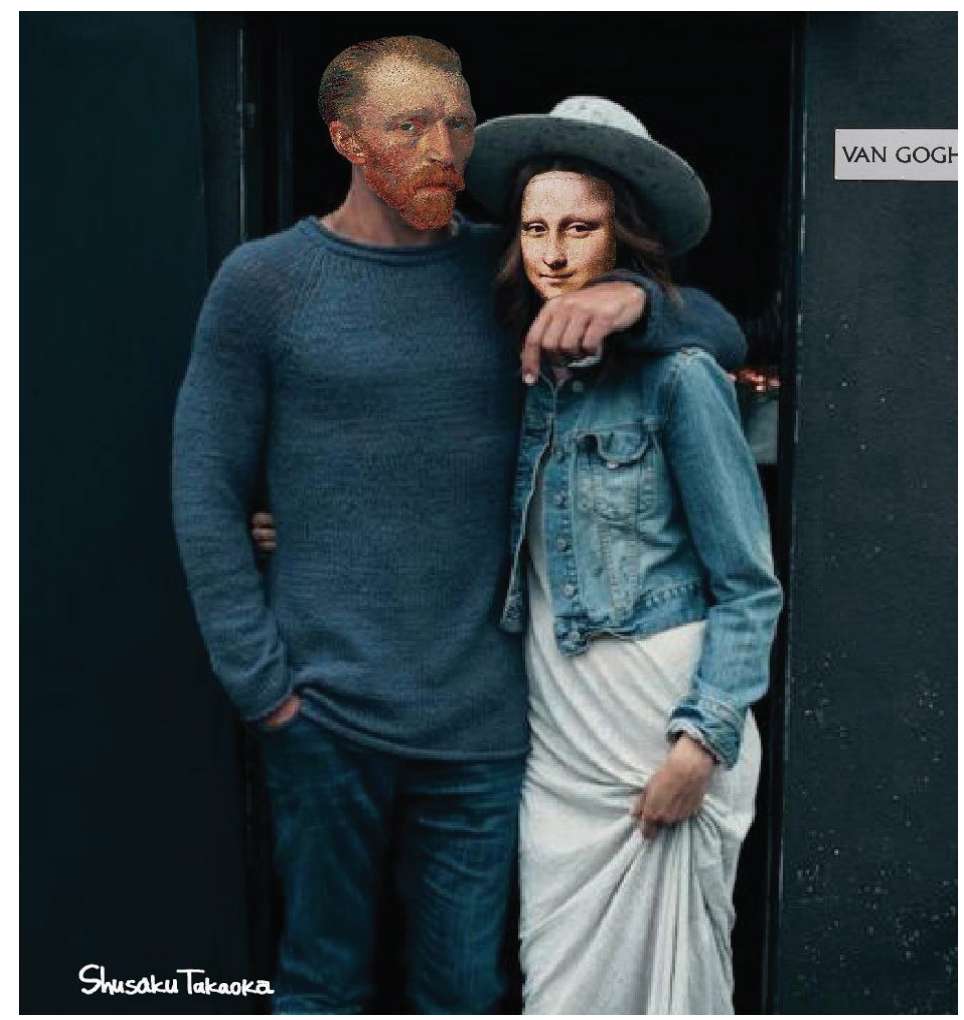

Figure 1. Shusaku Takaoka’s Van Gogh and Mona Lisa on Instagram. ${ }^{6}$

6 https://www.instagram.com/p/BSfirsoAQ7L/?taken-by=shusaku1977. 
(c) On Facebook, the same image, posted by Daily Art on 7 Aprill $^{7}$, counted 1989 shares, $3.8 \mathrm{k}$ likes and 61 comments. These numbers attest to the tendency of the visual content toward dissemination and sharing. Its reception was multi-layered: at the first level we find comments that express dissatisfaction: "Nope", "silly"; or emoticons which communicate disgust and dislike. At the second level, there are the posts that encapsulate appreciation through words such as "love", "amazing", "lovely couple", "cute couple", "two of my favourite peeps". Between the first and the second layers stands only the astonishment expressed in the comment "Whattttt?!?!". The third layer contains the irony expressed through posts such as: "What a modern couple" or "Is this the fake news with Mona Lisa?". A very interesting level is the fourth one, in which people rename the "personages": "VanLisa", "MonaGogh" (as a word play related to contemporary celebrities) as well as the collage itself: "The Goghna Lisa by Leonardo Da Vincent". Also, a photo with two users that copy the entire arrangement of the collage was posted as a response, stressing the virality and the insertion of the idea in a personal flux of life. The fifth layer of interpretation contains the comments that look for the reasons of choosing Van Gogh and Mona Lisa for the image ("I suppose that would be more a father relationship if we are to personify paintings", "for the contrast effect"). The last level contains some interesting meanings that correspond to contemporary social and cultural subjects of debate such as feminism, the role of women in society and the status of art between reification and exclusion ("Women in art still means women as subjects") or the allusion to a taboo subject - the age of the woman ("Mona is only a few centuries older!").

\section{Analysis of data gathered by focus group}

The sample consists of 13 subjects, students at the master module in Communication Studies at Alexandru Ioan Cuza University of Iasi, Romania. In order to cover the individual reception and understanding of images, as well as the group construction of meanings, I preferred the inclusion of a short questionnaire at the beginning of the meeting. Also, because the above posts on Facebook, Instagram and Tumblr contain at least one or more hashtags that indicate the name of the paintings or of their painters, I chose to continue the study in an offline setting, without giving my subjects any clue about the images. By doing this I excluded all possible identification cues. Besides the images selected and discussed above, for the focus group I chose to introduce a kind of control variable - a reaction

7 https://www.facebook.com/DailyArtApp/photos/a.306547722794289.73620.25270618484 5110/1267230056726046/?type $=3 \&$ theater. 
$\mathrm{GIF}^{8}$ - in order to observe if it functions as a semantic unit that has a definite and articulate signified, in comparison with art GIFs that have multiple meanings. Four images were discussed (two made by Shusaku Takaoka, that I have comprehensibly called Van Gogh and Mona Lisa ${ }^{9}$ and The Milkmaid and Starbucks ${ }^{10}$; one GIF after Van Gogh' At Eternity's Gate ${ }^{11}$; and the above-mentioned reaction GIF with Benedict Cumberbatch).

In order to synthetize the data gathered, I have divided the analysis in two main parts: (a) an "object-analysis" of the images (what are the signifieds associated with the given examples) and (b) a "meta-analysis" of GIFs as such (what are the signifieds associated with the GIFs in general).

(a) At the level of analysing the images, I observed the amplitude of meanings that all three images that contained paintings produced for the participants.

(1) As to Van Gogh and Mona Lisa (Fig. 1, studied also as regards Tumblr, Instagram and Facebook in the previous section), the majority of participants recognized correctly the two characters and also pointed out the synthesis of "photography and painting", "old and new", "past and present", "real values, and technology", "novelty and classic", "tradition and modernism". Two participants named it an "artistic collage", while one affirmed metaphorically that it represents "the postmodernism of Renaissance". One person labelled the image with the terms "caricature", "farce", and "joke". At the cognitive level, the dominant meanings were: "contrast", "innovation”, "antithesis", "novelty", "libertinism", "harmonisation”, "intermission", "partnership", "friendship", "sophistication", "reinterpretation", "cosmetic". At the affective level, the dominant ideas were: "amusement" (most frequent), "relaxation", "warmth", "simplicity", "stability", "silence", sophistication", "trust", "boredom", "curiosity", "tranquillity". At the reception level, I noticed similar reactions to those described on Instagram comments and expressed through the "why not?" interrogation.

(2) As to the second image, the recognition of the painting inserted in the collage failed totally, even if all the participants realized that they were, in fact, dealing with an insertion (one participant thought that it was Mother Teresa, while another thought about Vermeer's Girl with a Pearl Earring).

\footnotetext{
8 https://78.media.tumblr.com/95f84dc9c2d7a3e2d6b32e8a3d249b2b/tumblr_ ntygklBswV1uc8rl3o1_250.gif.

9 https://www.instagram.com/p/BSfirsoAQ7L/?taken-by=shusaku1977.

$10 \mathrm{https} / /$ www.instagram.com/p/BEVGtmasnZL/?taken-by=shusaku1977.

11 https://78.media.tumblr.com/f851941492248dcd699b21b9933e07cb/tumblr_ ox7avaswc41toamj8o1_500.gif.
} 


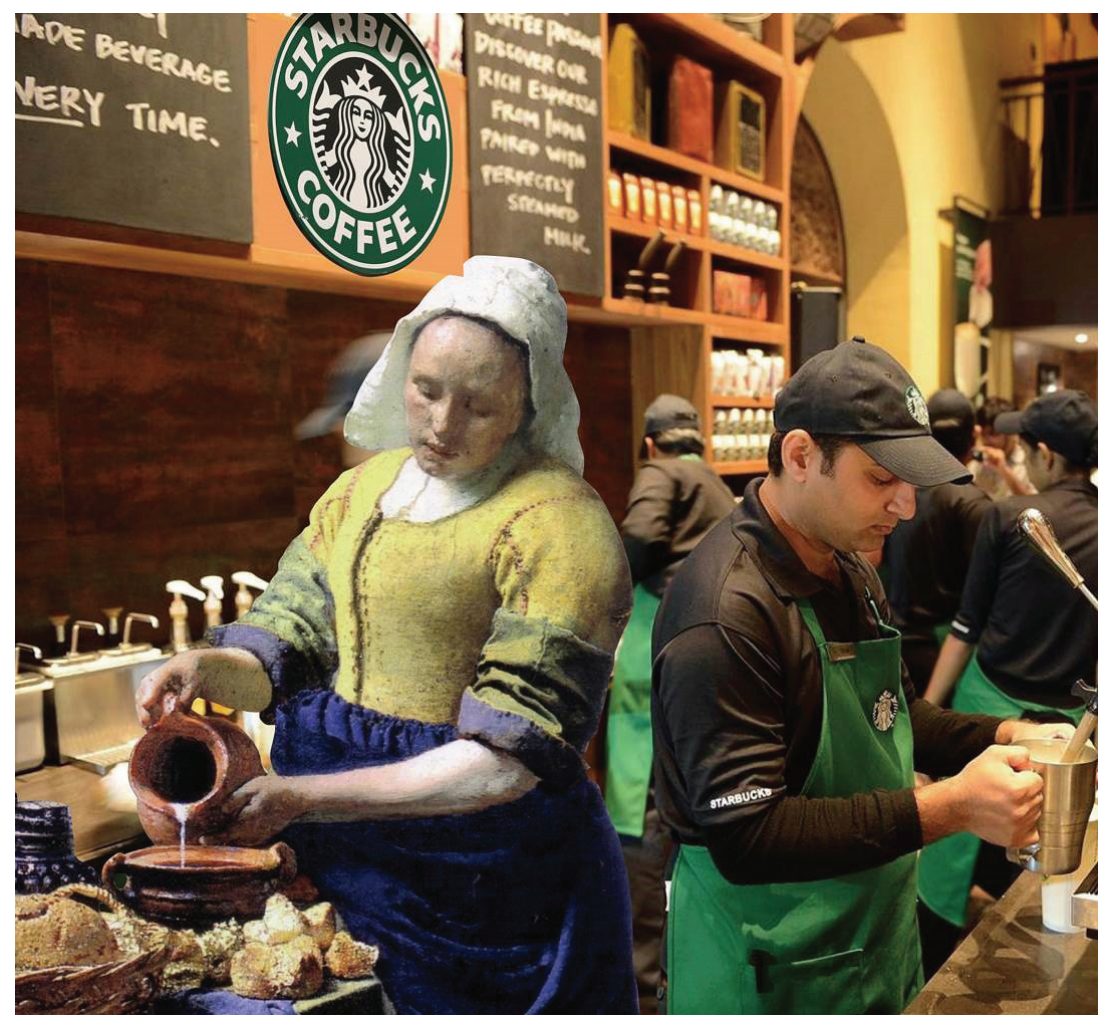

Figure 2. Shusaku Takaoka's The Milkmaid and Starbucks. ${ }^{12}$

The Starbucks logo was acknowledged by all the people, a situation completely expected given the educational background of the sample. Many respondents treated it as a possible ad or poster and as a new form of art. Also, the image was labelled as a collage that unites several antitheses. Anyhow, this image generated a more profound series of meanings, its reading driving toward the social interpretation of labour and the critique of the contemporary life characterized by haste, anxiety, and stress. At the cognitive level, the dominant meanings were the following: "the irony of the social development", "the client satisfaction", "coffee", "relish", "the meditative contemplation", "the contemporary in-a-hurry", "the continuity of things", "borderless collaboration regarding gender or class", "unity for profit", "the roots of modern things", "a manifest for the natural products", "performance marketing", "two worlds", "the slavery is not abolished, nor its form, but only its name has changed" or "history repeats itself". At the affective level, the

12 https://www.instagram.com/p/BEVGtmasnZL/?taken-by=shusaku1977. 
general tonality was dual: negative and positive. The participants were divided in stressing either the amusement, the jollity, and good feelings, or the sadness caused by the exposure to this content. Contemplation and nostalgic feelings were reported as well. One participant even remarked that she had polarized feelings, described as "pleasure" (she likes coffee) and "agitation" and "discomfort" at the same time. At the reception level, I also observed that the respective scale ranged from disagreement ("strange combination of epochs. I don't think they match") to acceptance ("important impact", "innovative image").

(3) The third image is an animated GIF that reinterprets Van Gogh's At Eternity's Gate.

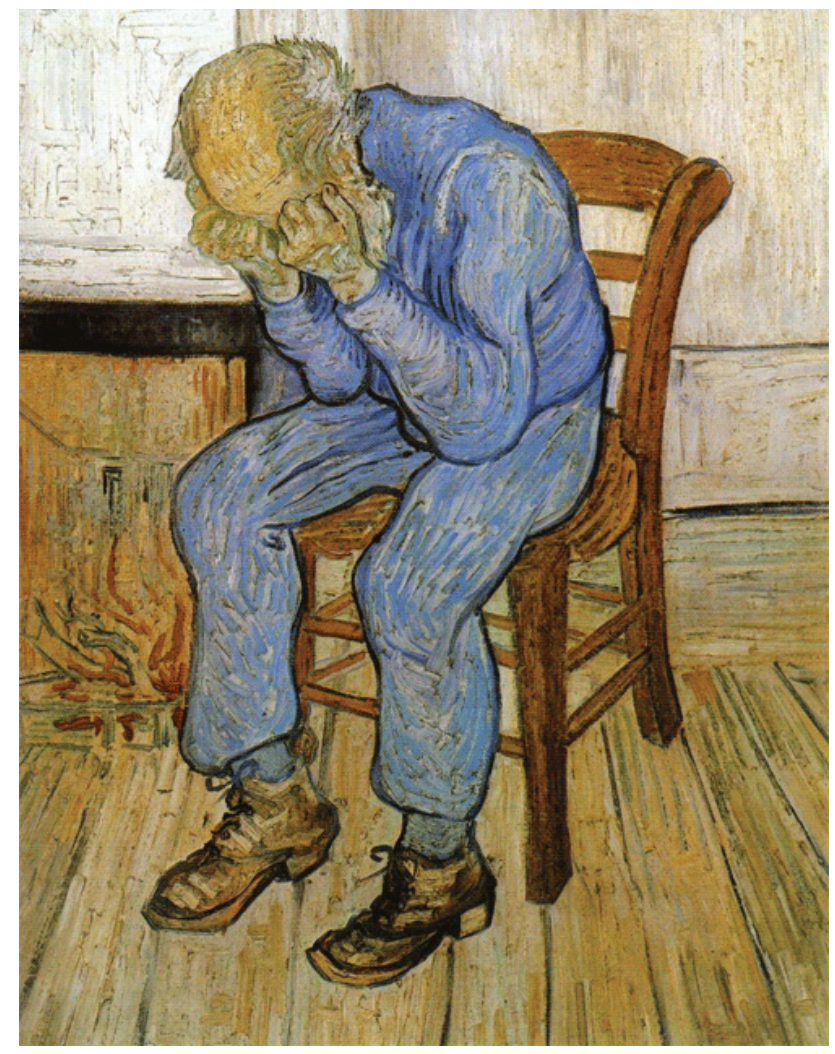

Figure 3. Van Gogh's At Eternity's Gate GIF on Tumblr. ${ }^{13}$

13 https://78.media.tumblr.com/f851941492248dcd699b21b9933e07cb/tumblr_ ox7avaswc41toamj8o1_500.gif. 
It produced a very emotional response from the participants, and that actually constituted the dominant level of discussion. One person claimed: "This has a powerful emotional impact!" Nevertheless, that does not mean at all that the meanings attributed to the GIF were the same. Rather, we can observe a more concentrated state of ideas, but no perfect unity of senses. Thus, the first cluster of meanings are formed by affective description, such as "sadness", "sufferance", "confusion", "grief", "weakness", "loneliness". The second cluster contains existentialist appreciations such as: "anxiety", "melancholy", "angst", "despair", and "bitterness". The third one is formed by metaphysical signifieds, such as "end" (of life) or "loss". The fourth cluster contains terms such as "pity", "tears", "pensive" (as emotional response to the GIF). At the cognitive level, the participants widely acknowledged the referent (the painter and not the movie Loving Vincent or other possible referrals), and integrated the GIF into a large domain of visual culture, arts, and aesthetics. At the reception level, all the participants express the emotional involvement: the GIF is "painfully sad". Also, the discussion expanded towards the social condition of the elderly who not only have to confront the idea of death, but, in many cases, clash with poverty, social exclusion and loneliness.

(4) The last GIF analysed is a classic example of animated reaction GIFs, presenting a well-known actor in a hilarious mood.

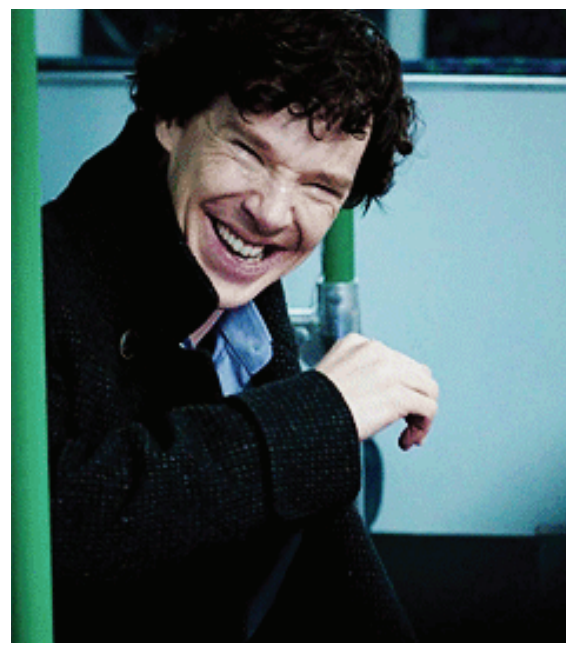

Figure 4. Benedict Cumberbatch's animated GIF. ${ }^{14}$

14 https://78.media.tumblr.com/95f84dc9c2d7a3e2d6b32e8a3d249b2b/tumblr ntygklBswV1uc8rl3o1_250.gif. 
My hypothesis was that to a great degree there would be consensus about its main signified (laughter). The hypothesis was confirmed, the majority of participants understood the GIF as a manifestation of joy, happiness, laugh or euphoria. Only three subjects thought that the GIF contained something more than a simple expression of amusement, namely: "an extreme irony", "insincerity", and "hypocrisy"; "stress"; "madness"; or "one maleficent element that produces fear".

(b) The meta-level of investigation followed a core question: What are the signifieds associated with the GIF considered as a form, in itself? One relevant observation that I made is that all the participants identified GIFs only with images in motion, totally excluding the static ones. Moreover, GIFs are considered either separately or simultaneously as means of communication, a form of art, a new media tool, a form of amusement and distraction. For the respondents, GIFs mean "short duration", "short animated movies that can be attached to messages", "a rapid way to transmit more information", "a modern form of expression", "short videos used on social networking sites in order to express more profound emotions than emoji could express", "creativity", "a dynamic way of presenting thoughts", "divertissement", "images in repetitive movement", "developed images", "illusion of movement", "an extension of emoticons", "more than a picture, less than a video".

Also, the participants use GIFs in online communication for three main purposes: for amusement, as a better way to communicate a detail or an emotion, and as a substitute for texting ("when I do not have ideas or I am not in the mood for typing"). Not all the opinions were positive - on the contrary, some voices criticized their superficiality and others criticized their role in communication.

In terms of advantages, the participants mentioned that GIFs represent creative tools that make communication more meaningful and "juicy", "dissipating the tension", being rapid, entertaining, and attractive.

As for the limits, the respondents accentuated the following points: their shortness, the inability to transmit a complex message, the possibility of annoying your interlocutor or the lack of sound. They were also characterized as fatiguing and in a way frustrating because "you want to see the movement till the end, but the finality is always interrupted". Even the repetitiveness (one main trait of GIF) was considered as a weakness, and, unlike the general opinion, this peculiarity has been depicted as the cause of its "limited memorability". Also, cyberspace was described as an agglomerated realm; the multitude of GIFs was perceived as a contributing factor in this situation.

One interesting point is that the participants emphasized the openness of interpretation and they put this trait in the category of "limits". To cite a participant: "GIFs may transmit a very different message in comparison with what 
you thought", while another stated: "they have double meanings frequently". Furthermore, the multitude of meanings that occurred points out the variety of interpretations and their inclusion in the category of 'floating signifiers'.

\section{The conclusions of the study}

In summary, the study was conducted in two main contexts of contemporary life, online (Tumblr, Instagram, Facebook) and offline, in order to have two different perspectives on the phenomenon examined. The online context preserved the clues of paintings used and reinterpreted in images, while in the offline investigation these clues were erased. This is the reason why the participants in offline settings failed to grasp the reference in case of the second and third images analysed. When the participants recognized the painting, its artist and other information related to it (cultural context, art movement, and historical context), the intertextuality was powerful and worked as a link between the original content and the actual use of it. At the same time, parody proved to be fruitful, because the receivers perceived the gap, the humour, the relocation of the meaning, which implies that a sign becomes meaningful within a cultural system. When the participants did not acknowledge these details, they could not connect all the references and the ironies, but still perceived that something "was wrong" with the picture and they were not able to ignore the contiguity of elements that did not belong to the same category. In this vein, the GIF still functions per se.

Many interpretations of images are deeply interwoven, even if they have been extracted from online comments or direct feedback. All the data indicate that particular instantiated images actually represent tokens of a Barthesian floating chain of signifieds. The investigation of particular GIFs and the meta-investigation of the signifieds of GIF tale quale assured that the treatment of art GIFs as floating signifiers is justified in particular cases, and also in general. I would assert that taking into consideration the inner characteristics of GIFs, these are in the same time both flickering and floating signifiers.

\section{Final remarks}

The article proposed to investigate GIFs and art collages as floating signifiers as they are articulated in particular discursive contexts, in offline as well as in online interactions. The different meanings attributed to this visual content portray and incarnate the peculiarities of the floating signifier. 
Strictly speaking, not all GIFs are floating signifiers and the analysis insisted upon the differences between reaction GIFs and art GIFs. Of course, art content has always been open to a plethora of interpretations and mixing it with a digital tool complicates matters even more. The emergence of interdisciplinary research can be helpful in the quest of deciphering composite objects of study that find themselves at the intersection of several types of literacies and competences. As we showed in the article, semiotics may provide a relevant set of tools that many other disciplines may use with significant results.

Divergences in the approach to this phenomenon are part of the complex framework of the study in which many factors intervene: the traits of online communication, the characteristics of GIFs, the heterogeneity of audience (their educational and cultural background). Cyberspace necessarily remains the framework of the debate in which controversies may lead to meaningful outcomes. Moreover, we can hope that the integration of the art work with popular forms of communication can lead to an improved mastering of aesthetic literacy, with a better knowledge of segments of art and culture. The subversive and anti-canon characteristics of GIFs can help to bring closer art and our everyday life and can prove promising as topics for possible thoroughgoing studies.

\section{References}

Andersen, Peter Bøgh 2001. What semiotics can and cannot do for HCI. Knowledge-Based Systems 14(8): 419-424.

Bakhshi, Saeideh; Shamma, David A.; Kennedy, Lyndon; Song, Yale; De Juan, Paloma; Kaye, Joseph J. 2016. Fast, cheap, and good: Why animated GIFs engage us. Proceedings of the 2016 CHI Conference on Human Factors in Computing Systems. ACM, 575-586.

Barthes, Roland 1977a. Rhetoric of the image. Image - Music - Text. (Heath, Stephen, trans.) London: Fontana Press, 32-51.

- 1977b. The third meaning. Image - Music - Text. (Heath, Stephen, trans.) London: Fontana Press, 52-68.

Baudrillard, Jean 1994. Simulacra and Simulation. (Glaser, Sheila Faria, trans.) Ann Arbor: University of Michigan Press.

Blair, Anthony J. 2014. The rhetoric of visual arguments. In: Hill, Charles A.; Helmers, Marguerite (eds.), Defining Visual Rhetorics. Mahwah: Lawrence Erlbaum Associates, 41-61.

Bolter, Jay David; Grusin, Richard 1999. Remediation. Understanding New Media. Cambridge, London: MIT Press.

Burgess, Jean 2006. Hearing ordinary voices: Cultural studies, vernacular creativity and digital storytelling. Journal of Media and Cultural Studies 20(2): 201-214.

Carpentier, Nico; De Cleen, Benjamin 2007. Bringing discourse theory into media studies: The applicability of discourse theoretical analysis (DTA) for the study of media practises and discourses. Journal of Language and Politics 6(2): 265-293. 
Eppink, Jason 2014. A brief history of the GIF (so far). Journal of Visual Culture 13(3): 298-306. Furht, Borko 2008. Encyclopedia of Multimedia. (2nd ed.) New York: Springer.

Gillan, Jennifer 2016. Textural poaching Twin Peaks: The Audrey Horne Sweater Girl GIFs. Series-International Journal of TV Serial Narratives 2(2): 9-24.

Gürsimsek, Ödül Akyapi 2016. Animated GIFs as vernacular graphic design: Producing Tumblr blogs. Visual Communication 15(3): 329-349.

Halliday, Mak 1978. Language as Social Semiotic: The Social Interpretation of Language and Meaning. London: Edward Arnold.

Halpin, Harry; Thompson, Henry S. 2009. Social meaning of the web: From Wittgenstein to search engines. IEEE Intelligent Systems 6: 27-31.

Hayles, Katherine N. 1993. Virtual bodies and flickering signifiers. October 66: 69-91.

- 1999. How We Became Posthuman. Virtual Bodies in Cybernetics, Literature, and Informatics. Chicago: Chicago University Press.

Highfield, Tim; Leaver, Tama 2016. Instagrammatics and digital methods: Studying visual social media, from selfies and GIFs to memes and emoji. Communication Research and Practice 2(1): 47-62.

Jenkins, Henry 2006. Convergence Culture: Where Old and New Media Collide. New York: New York University Press.

Kress, Gunther 2003. Literacy in the New Media Age. London: Routledge.

Lacan, Jacques 1955. Les structures freudiennes des psychoses. Le Séminaire, Livre III (19551956), Les psychoses. Paris: Le Seuil.

Laclau, Ernesto 1996. Emancipation(s). London: Verso.

- 2000. Constructing universality. In: Laclau, Ernesto; Butler, Judith; Žižek, Slavoj 2000. Contingency, Hegemony, Universality: Contemporary Dialogues on the Left. London: Verso, 281-307.

- 2005. On Populist Reasons. London: Verso.

Laclau, Ernesto; Mouffe Chantal 1985. Hegemony and Socialist Strategy: Towards a Radical Democratic Politics. London: Verso.

Lévi-Strauss, Claude 1987. Introduction to the Work of Marcel Mauss. (Baker, Felicity, trans.). London: Routledge.

Lunenfeld, Peter 2000. Snap to Grid: A User's Guide to Digital Arts. Cambridge: The MIT Press.

- 2001. The Digital Dialectic: New Essays on New Media. Cambridge: The MIT Press.

Makarychev, Andrey S. 2012. Human security as a 'floating signifier': Russia's re-interpretation of the concept. In: Martin, Mary; Kaldor, Mary; Serra, Narcis (eds.), National, European and Human Security: From Co-existence to Convergence. London: Routledge, 152-166.

Manovich, Lev 2001. The Language of New Media. Cambridge: The MIT Press.

Mehlman, Jeffrey 1972. The 'floating signifier': From Lévi-Strauss to Lacan. Yale French Studies 48: $10-37$.

Mohr, Richard 2006. Living legal fictions: Constituting the state or submerging the signifier? International Journal for the Semiotics of Law 19(3): 237-258.

Moraes, Silvia Elisabeth 2014. Global citizenship as a floating signifier: Lessons from UK universities. International Journal of Development Education and Global Learning 6(2): 27-42.

Nusselder, André 2009. Interface Fantasy: A Lacanian Cyborg Ontology. Cambridge: The MIT Press.

Rodowick, David N. 2001. Reading the Figural, or, Philosophy after the New Media. Durham: Duke University Press. 
Rourke, Daniel 2012. The doctrine of the similar (GIF GIF GIF). Dandelion 3(1): 1-5.

Taylor, Pamela G. 2004. Hyperaesthetics: Making sense of our technomediated world. Studies in Art Education 45(4): 328-342.

Tolins, Jackson; Samermit, Patrawat 2016. GIFs as embodied enactments in text-mediated conversation. Research on Language and Social Interaction 49(2): 75-91.

Topolski, Anya 2014. Spinoza's true religion: The modern origins of a contemporary floating signifier. Society and Politics 8(1): 41-59.

Uhlin, Graig 2014. Playing in the gif(t) economy. Games and Culture 9(6): 517-527.

Žižek, Slavoj 1989. The Sublime Object of Ideology. London: Verso.

\section{Images, GIFs}

Takaoka, Shusaku 2017. Van Gogh and Mona Lisa. Available at https://www.instagram.com/p/ BSfirsoAQ7L/?taken-by=shusaku1977.

DailyArt 2017. Van Gogh and Mona Lisa. Available at https://www.facebook.com/DailyArtApp/ photos/a.306547722794289.73620.252706184845110/1267230056726046/?type=3\&theater.

Tumblr. GIF. Available at https://78.media.tumblr.com/95f84dc9c2d7a3e2d6b32e8a3d249b2b/ tumblr_ntygklBswV1uc8rl3o1_250.gif.

Takaoka, Shusaku 2016. The Milkmaid and Starbucks. Available at https://www.instagram. $\mathrm{com} / \mathrm{p} /$ BEVGtmasnZL/?taken-by=shusaku1977.

Tumblr. At Eternity's Gate GIF. Available at https://78.media.tumblr.com/ f851941492248dcd699b21b9933e07cb/tumblr_ox7avaswc41toamj8o1_500.gif.

\section{ГИФы (GIFs) как плавающие означающие}

Данная статья исследует гифы, которые используют знаменитые картины и художественные коллажи, чтобы установить возможность их интерпретации в качестве 'плавающих означающих'. Здесь объясняется понятие 'плавающего означающего' и описываются изменения в его значении, когда термин применили к информационным единицам и дигитальной материальности. Так, например, в новой медии параллельно с 'плавающим означающим' пользуются термином Хейлс 'мерцающее означающее'. Незаметно качества гифов превращают гиф в прекрасную иллюстрацию обоих понятий. Также в статье рассматривается главный “портрет” гифов, их последствия и основные корреляции. Гифы изучались как в онлайновых (Tumblr, Instagram, Facebook), так и в офлайновых дискурсах. Означаемые, которые приписываются конкретным гифам и гифам вообще, очерчивают их профиль в качестве плавающих означающих.

\section{GIF-id kui ujuvad tähistajad}

Artiklis uuritakse GIFe, mis kasutavad kuulsaid maale ja kunstikollaaže, et teha kindlaks, kas nende võimalikud tõlgendused õigustavad GIF-ide nimetamist 'ujuvateks tähistajateks'. Sel eesmärgil selgitan, mida tähendab 'ujuv tähistaja', ja kirjeldan, mis juhtus selle terminiga, kui see viidi korrelatsiooni informatsiooni ja digimateriaalsuse küsimustega. Nii on uusmeedias 'ujuva tähistaja' paralleelterminiks Haylesi 'vilkuv tähistaja'. Märkamatult muudavad GIF-i omadused selle mõlema mõiste täiuslikuks kehastajaks. Artiklis puudutatakse ka GIF-ide peamist 
“portreed", nende implikatsioone ja olulisi korrelatsioone. GIFe vaadeldakse nii võrgusiseses (Tumblr, Instagram, Facebook) kui ka võrguvälises diskursiivses kontekstis. Tähistatavad, mida omistatakse konkreetsetele GIF-idele, ning GIF-dele üldse, visandavad nende profiili ujuvate tähistajatena. 